\title{
Herpes zoster case report
}

\author{
Hajar O Ali, Yousif I Eltohami, Amal H Abuaffan* and Shiraz Altigani \\ Faculty of Dentistry, Department of Orthodontics, Pedodontics and Preventive Dentistry, University of Khartoum, Sudan
}

\section{Introduction}

Chickenpox and herpes zoster disease are caused by the same virus, the varicella-zoster virus $(\mathrm{VZV})$, which is another member of the herpes viruses.

Subsequent infection by chickenpox, the virus remains latent in the sensory ganglia probably for the reminder of the host's life. Reactivation of the virus to cause zoster is uncommon but may occur apparently spontaneously or when the host defenses are depressed. The lesions are usually localized to the distribution of one or more sensory nerves. The characteristic unilateral vesicular eruption is frequently preceded by prodromal symptoms of pain and par aesthesia for up to two weeks [1].

\section{Case report}

A 50 years old male came to dental clinic complaining of swelling at the right side of the face. The condition started two weeks ago associated with toothache that aggravated by cold water. The toothache had been treated by a dentist conservatively, two days later swelling appeared and became large and larger on the following days with vesicular eruptions and discharging a yellowish material at same side of the face in addition to bloody discharge from the ear. Fortunately, the vesicles did not cross the midline. He consults another dentist who prescribed antibiotics Then he went back to the dentist who prescribed antibiotics and analgesic and referred him to Faculty of dentistry for consultation and treatment.

Regarding the past medical history there is no clinical significance.

On examination the patient was looked fatigue. There were crusted ulcerations with reddish margins at the right side of the face and ulcers with discharge fluid at the chin area and yellowish discharge from the ear. Although there no tender on the lesion (Figure 1-5).

There were small whitish ulcerations that can't be rupped off and not tender at the right side of buccal mucosa, tongue and the hard palate.

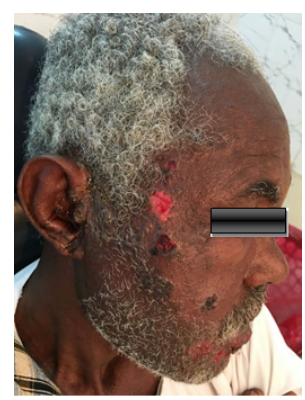

Figure 1. Showed herpes zoster vesicles at the right side of the face and auricle.

\section{Investigations}

Random blood glucose, viral screening and complete blood count were done and all the results were normal.

\section{Treatment}

The patient was admitted to hospital and given I.V fluids to treat the dehydration together with intravenous infusion of antibiotics to prevent super infection, oral antiviral drug (acyclovir $400 \mathrm{mg} / 5 \mathrm{hrs}$ ) for two weeks and topical acyclovir for the lesions. Then after 2 days from treatment the I.V antibiotics and fluids were stopped and the patient discharged from hospital and oral antibiotics was prescribed for him beside the antiviral drugs.

\section{Outcome}

After 1 week of treatment the patient became well and the ulcers was almost healed.

But after 2 weeks the patient came complaining of severe itching at the site of lesions which is relieved by anti-itching agent (calamine lotion) (Figure 6 and Figure 7).

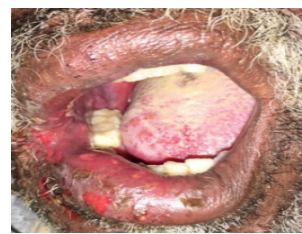

Figure 2. Showed herpes zoster vesicles at the right side of both upper and lower lip.

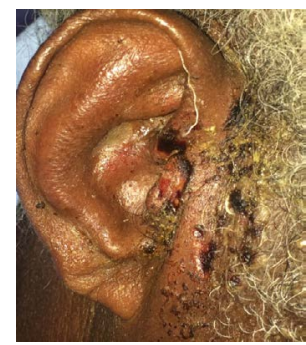

Figure 3. Shows yellowish discharge from the right ear.

Correspondence to: Amal H Abuaffan, Faculty of Dentistry, Department of Orthodontics, Pedodontics and Preventive Dentistry, University of Khartoum, Sudan, Tel: 00249912696035; E-mail: amalabuaffan@yahoo.com

Received: August 19, 2016; Accepted: September 16, 2016; Published: September 19, 2016 


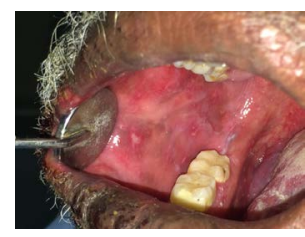

Figure 4. Shows whitish ulcerations on the right buccal mucosa.

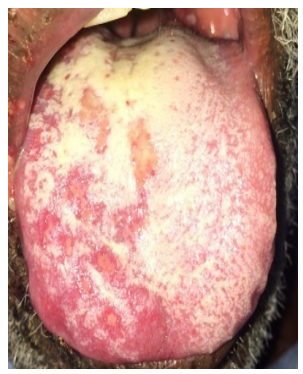

Figure 5. Showed whitish ulcerations on the right side of tongue.

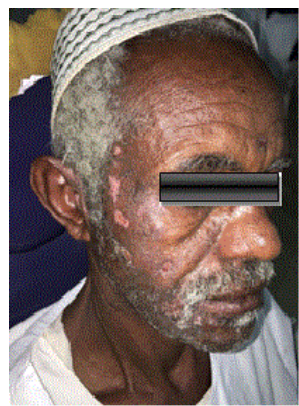

Figure 6. Shows status of the patient after 2 days from receiving the treatment.
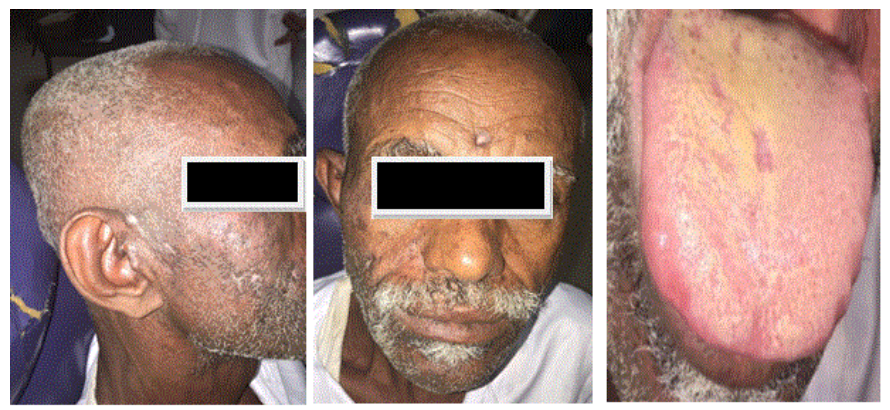

Figure 7. Shows status of the patient after 1 week from receiving the treatment.

\section{Discussion}

A typical untreated herpes zoster outbreak frequently requires a minimum of 30 days to fully resolve. In many instances, resolution can take much longer. The common timeline for shingle is a 2 to 3 days prodromal phase, followed by 3-4 days for the rash to form into vesicles or blisters [2]. Fluid inside the blisters is initially clear, but may become cloudy after 3-4 days. After another 5 days, the blisters begin erupting, secreting fluid, and subsequently drying out and forming a crust. Complete healing typically takes another 2-4 weeks [3].

Oral acyclovir and related compounds are the most common firstline treatment for a herpes zoster outbreak, but these agents have often been proven only moderately effective in clinical settings. A clinical study demonstrated that acyclovir - dosed at $800 \mathrm{mg}, 5$ times daily for 7-10 days - had no statistically significant effect on acute pain after 1 month [4]. Acyclovir was associated with a decrease in overall healing time of herpes zoster when compared to a placebo, but only by 1-2 days. Another study, ${ }^{5}$ which compared valacyclovir with acyclovir, showed that valacyclovir healed the rash by day 15 , with complete healing by day 22. This was better than acyclovir's healing time of 29 days, but still demonstrated only moderate efficacy [5].

Acyclovir, like many pharmaceutical-grade treatments, have common, as well as serious, side effects associated with their use. Acyclovir's side effects can include a general ill feeling, nausea or vomiting, diarrhoea, headaches, and the more concerning side effects of seizures, hallucinations, and possible allergic reactions. In another case study the topical herbal formulation used presented with no adverse reactions when used on the patient during the treatment protocol [6]. This may support the use of these antiviral/analgesic herbs for topical application on immunocompromised patients infected with VZV, who represent one of the largest populations affected by herpes zoster. With acyclovir being so commonly used to treat VZV, it is not surprising that numerous studies illustrate the frequent development of drug-resistant herpes viruses in clinical settings, particularly in immunocompromised patients. When using a mono-therapy like acyclovir, a virus is often more likely to gain resistance, as compared to a combination therapy $[7,8]$ such as a multi-herbal formulation, since numerous different constituents are present to inhibit viral replication.

\section{References}

1. Somes JV and Southam JC (2004) Oral pathololgy. Academic 155-156.

2. Dworkin RH, Johnson RW, Breuer J, Gnann JW, Levin MJ, et al. (2007) Recommendations for the management of herpes zoster. Clin Infect Dis 44 Suppl 1: S1-26. [Crossref]

3. Janniger CK, et al. (2016) Herpes Zoster Clinical Presentation. Medspace.

4. Opstelten W, Eekhof J, Neven AK, Verheij T (2008) Treatment of herpes zoster. Can Fam Physician 54: 373-377. [Crossref]

5. Raju GN, Raza M, Kumar TN, Singh G (2011) Comparative study of the efficacy of valacyclovir and acyclovir in herpes zoster. Int J Pharm Biomed Res 2:119-123.

6. Bertram L Jacobs, et al. (2015) A case report of botanical treatment of shingle. Southwest College of Naturopathic Medicine. Tempe.

7. Andrei G, Fiten P, De Clercq E, Snoeck R, Opdenakker G (2000) Monitoring drug resistance for herpesviruses. Methods Mol Med 24: 151-169. [Crossref]

8. Gilbert C, Bestman-Smith J, Boivin G (2002) Resistance of herpesviruses to antiviral drugs: clinical impacts and molecular mechanisms. Drug Resist Updat 5: 88-114. [Crossref]
Copyright: (C2016 Ali HO. This is an open-access article distributed under the terms of the Creative Commons Attribution License, which permits unrestricted use, distribution, and reproduction in any medium, provided the original author and source are credited. 